\title{
The Effect of Supplemented Pellet Binders in Broiler Compound Diets on Fattening Performance and Pellet Quality Criteria
}

\author{
Songul Senturklu (Corresponding author) \\ Canakkale Onsekiz Mart University, BMYO, Canakkale, Turkey \\ E-posta:songuls2011@hotmail.com \\ Murat Zincirlioglu \\ Ankara University, Faculty of Agriculture, \\ Department of Animal Science, Ankara, Turkey
}

\begin{abstract}
This study aimed at examining the effects of some pellet binders used in broiler compound feeds on pellet quality and broiler performance. The research was organized in two stages, namely biological experiment and laboratory study. Experiment compound feeds were prepared as one powder and three pellet forms. One pellet group of compound feed was pelleted with only steam and the other two groups were pelleted with same amount Aquacube and Ligno Bond pellet binders. At the end of the experiment, average live weight (CA), live weight gain (CAA), feed consumption (YT) and feed evaluation (YDS) were determined in broilers. As a result of analysis of variance among the groups, there was no significant difference in CA, CAA and YT ( $\mathrm{P}>0.05)$. The differences in the number of YDS 1.77, 1.66, 1.64, and 1.58 , respectively were significant $(\mathrm{P}<0.05)$. According to the results of pellet quality analysis; pellet durability (D) $79.8 \%, 87.7 \%, 88.9 \%$, powder feed (TY) percentage $16.8 \%, 15.7 \%, 14.8 \%$ and percent moisture contents (NI) $10.9 \%, 11.4 \%$ and $11.2 \%$ respectively was determined in the pelleted 2 nd, 3rd and 4th feed groups. Better YDS was found in all broiler groups fed with pellet feed. The pellet binders used in the pelleting of the compound feeds increased the pellet quality. At the same time broiler performance improved with increasing pellet quality.
\end{abstract}

Keywords: Compound feed, broiler performance, pellet binders, pellet quality criteria.

DOI: $10.7176 / J S T R / 5-11-08$

\section{Broyler Karma Yemlerine İlave Edilen Pelet Bağlayıcılarının Besi Performansı ve Pelet Kalite Kriterleri Üzerine Etkisi"}

\section{Özet}

$\mathrm{Bu}$ araştırmada broyler karma yemelerinde kullanılan bazı pelet bağlayıcılarının pelet kalitesine ve broyler performansı üzerine etkileri incelenmiştir. Araştırma, biyolojik deneme ve labratuvar çalışması olmak üzere iki aşamada düzenlenmiştir. Deneme karma yemleri bir toz ve üç pelet form olarak hazırlanmıştır. Bir grup karma yem sadece buharla, diğer iki gruba ise aynı miktarda Aquacube ve LignoBond pelet bağlayıcıları ile peletlenmiştir. Deneme sonu itibariyle broylerlerde, ortalama canlı ağırlık (CA), canlı ağırlık artış (CAA), yem tüketimi (YT) ve yem değerlendirme sayısı (YDS) tespit edilmiştir. Gruplar arasında yapılan varyans analizi sonucunda CA, CAA ve YT bakımından önemli farklılık çıkmamışıı $(\mathrm{P}>0.05)$. Ancak YDS bakımından gruplar arsındaki farklılıklar sırasıyla 1.77, 1.66, 1.64 ve 1.58 olarak önemli çıkmıştır $(\mathrm{P}<0.05)$. Pelet kalite analiz sonuçlarına görede; peletlenmiş 2., 3 ., ve 4. yem grupların da sirasıyla pelet dayanıklılığı (D), $\% 79.8, \% 87.7, \% 8.9$, toz yem (TY) yüzdesi $\%$ $16.8, \% 15.7, \% 14.8$ ve yüzde nem içerikleri (NI) $\% 10.9, \% 11.4$ ve $\% 11.2$ olarak belirlenmiştir. Pelet yemlerle beslenen tüm broylerlerde YDS bakımından daha iyi sonuçlar tespit edilmiştir. Karma yemlerin peletlemesinde kullanılan pelet bağlayıcıları pelet kalitesini arttırmıştır. Aynı zamanda artan pelet kalitesiyle birlikte YDS iyileşmiştir.

Anahtar kelimeler; Karma yem, broyler performansı, pelet bağlayıcıları, pelet kalite kriterleri "Songul Senturklu' nün doktora tezinden özetlenmiştir.

59 | P a g e

www.iiste.org 


\section{Giriş}

Kanatlı hayvan beslemesinde toplam maliyetinin \% 60-70' ini yem giderleri oluşturmaktadır (Behnke ve Beyer, 2002), bu sebeple broyler üretiminde yemin verimli kullanımı son derece önemlidir. Bu amaçla da peletleme işlemi uzun yıllardır broyler yem endüstrisinde yaygın olarak kullanılan bir ısıl işlem yöntemidir (Moritz ve ark., 2001; Jahan ve ark., 2006; Amerah ve ark., 2008). Kanatlı kümes hayvanlarının, pelet ve crumble yemi toz yeme nazaran daha istekli tükettikleri, peletlenmiş karma yem içeriğinden daha çok yararlandıkları pek çok araştırmacı tarafından ileri sürülmüştür (Allred ve ark., 1957; Mcintosh ve ark., 1962; Callet, 1965; Nir ve ark., 1990; Nir ve ark., 1994a-b; Payne ve ark., 1994; Cox ve ark., 1986; Basmacıŏ̆lu, 2004; Dozier ve ark., 2010; Chewning ve ark., 2012). Ayrıca pek çok araştırma sonucunda da, pelet yada crumble yemlerle beslenen broylerler de CA, YT ve özelliklede YDS `ında artış olduğu bildirilmişdir (Acar ve ark., 1991; Reddy ve Narahari 1993; Sıddıquie ve ark., 1994; Jensen, 2000; Jahan ve ark., 2006; Amerah ve ark., 2008; Chewning ve ark., 2012). Ayrica Pejin ve Supic, (1989), Zatari ve Seti (1990), McKinney ve Teeter (2004) ve Lemme ve ark., (2006) da, pelet yemle beslenen broylerlerde 42. günde daha fazla canlı ağırlık ve yem dönüşüm etkinliği (YDS) oranı elde etmişlerdir. Hatta Neves ve ark., (2014), yaptıkları derleme sonucunda peletlenmiş yem düşük kalitede olsa bile toz yemden daha fazla avantaja sahip olduğu sonucuna varmışlardır.

Yine Kim ve ark., (1996), Jahan ve ark., (2006), Mirghelenj ve Golian (2009) ve Zang ve ark., (2009) tarafindan, crumble yada pelet yem formu ile beslenen broylerlerde yem dönüşüm etkinliğinin (YDS) önemli ölçüde artığ 1 tespit edilmiştir. Araştırmacılar, pelet yem formunun broylerlerde hem performansı iyileştirdiği hem de sindirim kanalının gelişmesine katkı sağladığını bildirmişlerdir (Mingbin ve ark., 2015). Ayrıca pellet formda yem tüketen broylerlerde de yem seçimi ve israfının azaldığ 1 , yem yemek için harcanacak enerjinin daha düşük olmasından dolayı tasarruf edilen enerjinin büyüme için kullanılacağı, aynı zamanda peletlemenin patojenleri yok ederek lezzetliliği iyileştirdiği ve besinlerin sindirilebilirliğini artırarak broyler performansını arttırdığını bildirilmektedirler (Calet, 1965; Preston ve ark., 2000). Bazı araştırmacılarda, peletleme işleminin hem karma yem üreticilerine fayda sağladığını hem de broylerlerin yem tüketimini ve yem değerlendirmesini olumlu etkilediğini bildirmişlerdir (Jensen, ve ark., 1962; Behnke, (1996).

Pek çok araştırmacılar da pelet formda yemle beslenen broylerlerin performans değerlerindeki bu avantajların ancak kaliteli üretilmiş pelet yemlerle sağlanabileceğini savunarak (Briggs ve ark., 1999), pelet yem kalitesini arttıracak pek çok farklı yöntemler önermişlerdir (Behnke, ve Beyer, 2002; Moritz ve ark., 2003; Hott ve ark., 2008; Keysuke ve ark., 2015). Bu yöntemlerden bazıları peletlenme sistemi ve teknikleriyle ilgili iken, bazıları da yem katk1 maddeleriyle ilgilidir. Yem katk1 maddesi olarak kullanılan pelet bağlayıcılarının, karma yem üretim aşamasında karşıllaşılan bazı olumsuzlukları gidereceği, pelet yemlerin objektif ve subjektif kalite kriterlerinin yanı sıra broylerlerde yemden yararlanmayı artıracağı ileri sürülmüştür (Moran, ve ark., 1989; Ensminger ve ark., 1990; Acar ve ark., 1991; Castaing, 1994; Das ve ark., 1993; Ergül, 1994; Labao ve ark., 1993; Castolda ve Clayton, 1995; Corey ve ark., 2014; Attar ve ark., 2018; Mohammad ve ark., 2019a,b).

Proudfoot ve ark., (1979) ve Acar ve ark., (1991), lignosülfonat bağlayıcıları ile yaptıkları araştırmada bağlayıcıların broyler performansı üzerine ek olarak herhangi bir etkisinin olmadığını bildirmemişlerdir. Corey ve ark., (2014) ve Wamsley ve ark., ( 2014) ise, pelet yeme ilave ettikleri \% 0,5 CaLS ile pelet kalitesinin arttığını ve buna bağllı olarak da broylerlerde yem dönüşümünü artırdığını bildirmişlerdir $(\mathrm{P}<0.05)$. Waldroup, (982), Hopf ve Vorher, (1994), Payne ve ark., (1994), Angulo ve ark., (1995) ve Castaldo ve ark., (1995), farklı tür pelet bağlayıcısı ile hazırladıkları peletlerde pelet kalitesinin arttığı, mısır-soya esaslı ve yüksek oranda yağ içeren karma yemlerde bağlayıcı kullanılması gerektiğini savunmuşlardır. Arash ve ark., (2018)`da bentonit, bugday ve buğday gluteni içerikli pellet yemlerde bağlayıcıların fiziksel kaliteyi ve broyler performansını artırdığını bildirmiştir. Mohammad ve ark., (1919b) tarafindan da, Bentonit ve Calsiıyum Lignosülfanat kullandıkları farklı oranda yağ içerikli broyler karma yemlerinde pelet kalite kriterlerini önemli ölçüde artırdığ tespit edilmiştir.

Bununla birlikte, yemin fiziki formunun broylerler performansı üzerine herhangi bir olumlu etkisinin olmadığını bildiren araştırma sonuçları da vardır (McAllister ve ark., 2000; Svihus ve ark., 2004; Galobart ve Morant, 2005; Salari ve ark., 2006; Reace ve ark., 1986).

$\mathrm{Bu}$ araştırmanın amacı, broyler karma yemlerinin peletlenmesinde kullanılan bazı pelet bağlayıcılarının pelet kalitesine ve broyler performansına etkilerinin incelenmesidir.

\section{Materyal ve Yöntem \\ Hayvan materyali}

Araştırmada hayvan materyali olarak 180 adet günlük yaşta, karışık cinsiyette Hubbard broyler civcivleri kullanılmıştır.

$60 \mid \mathrm{P}$ a g e

www.iiste.org 


\section{Yem materyali}

Araştırmada kullanılan karma yemler broylerlerin besin maddesi ihtiyaçlarını karşılayacak şekilde (Doğan, 1993; NRC, 1994) çizelge 2.1 'de ki içeriğe göre hazırlanmıştır. Pelet bağlayıcıları olarak LignoBond (bitki kaynaklı çözünür lif yapısında olan \% 100 lignosülfonat içerikli) ve Aquacube (sentetik sakız ve hidratlı kalsiyum sülfat içerikli) kullanılmıştır. Deneme planına göre karma yemler, pelet, crumble ve toz formda hazırlanmıştır. Bütün dönemlerde bir gurup yem daima toz formda (1.gurup), diğer guruplar da curmble yada pellet formda (2., 3. ve 4. guruplar) hazırlanmıştır. 1. gurup yem sadece buharla muamele edilerek, diğer iki gurup da sırasıyla Aquacube ve LignoBond pelet bağlayıcısı ilave edilerek peletlenmiştir. Civciv başlangıç döneminde pelet yemler crumble formada hazırlanmıştır.

\section{Yöntem}

Araştırma 4 yem gurubu ve her bir gurupta 6 alt gurup olacak şekilde tesadüf parselleri deneme tertibine göre planlanmıştır. Her guruba, ortalama canlı ağırlık ve cinsiyet bakımından homojen olan günlük yaştaki 45 adet civciv tesadüfi olarak dağıtılmıştır.

Araştırmada kullanılan yem hammaddelerinin ham besin maddesi analizleri Weende analiz metotlarına göre (Akyıldız, 1984), nişasta ve şeker analizleri de Nauman and Bassler (1976) tarafindan bildirilen metoda göre yapılmıştrr. Araştırmada kullanılan karma yemlerin kompozisyonu tablo 2.1 de ve ham besin maddesi analizlerine ait verilerde tablo 2.2 'de verilmiştir.

Tablo 2.1. Araştırmada kullanılan karma yemlerin kompozisyonu

\begin{tabular}{|c|c|c|c|c|}
\hline $\begin{array}{l}\text { Ham maddeler } \\
(\mathrm{Kg} / \mathbf{1 0 0 0})\end{array}$ & $\begin{array}{l}\text { Civciv } \\
\text { Başlangıç }\end{array}$ & $\begin{array}{l}\text { Piliç } \\
\text { Geliştirme }\end{array}$ & $\begin{array}{l}\text { Piliç } \\
\text { Geliştirme }\end{array}$ & $\begin{array}{l}\text { Kesim } \\
\text { Öncesi }\end{array}$ \\
\hline Misır & 496.4 & 535.52 & 558.69 & 574.02 \\
\hline Yağlı soya & 50.00 & 60.00 & 75.00 & 90.00 \\
\hline Soya (48) & 298.14 & 240.12 & 203.96 & 187.24 \\
\hline Ayçiçeği tohumu küspesi (32) & 20.05 & 29.21 & 20.0 & 14.94 \\
\hline Balık unu (72) & 28.47 & 10.00 & 17.19 & - \\
\hline Et kemik unu & - & - & - & 10.0 \\
\hline Tavuk unu & 25.00 & 30.00 & 30.00 & 35.00 \\
\hline Dikalsiyum fosfat & 12.60 & 14.42 & 13.89 & 11.94 \\
\hline Vitamin ve mineral premiksi* & 10.00 & 10.00 & 10.00 & 10.00 \\
\hline Mermer tozu & 10.42 & 10.32 & 9.02 & 6.96 \\
\hline Don yă & - & - & - & 9.35 \\
\hline Yă̆ & 44.00 & 51.96 & 54.05 & 43.88 \\
\hline Tuz & 2.57 & 2.75 & 2.70 & 2.92 \\
\hline Metionin & 2.36 & 2.38 & 2.19 & 1.49 \\
\hline L.Lisin & - & 1.32 & 1.24 & 0.26 \\
\hline Pelet bağlayıcıları & 20.0 & 20.0 & 20.0 & 20.0 \\
\hline Toplam (Kg) & 1000.00 & 1000.00 & 1000.00 & 1000.00 \\
\hline
\end{tabular}


Tablo 2.2. Araştırmada kullanılan karma yemlerin ham besin maddesi içerikleri

\begin{tabular}{|c|c|c|c|c|}
\hline Ham besin maddesi içerikleri & $\begin{array}{l}\text { Civciv } \\
\text { Başlangıç }\end{array}$ & $\begin{array}{l}\text { Piliç } \\
\text { Geliştirme }\end{array}$ & $\begin{array}{l}\text { Piliç } \\
\text { Geliştirme }\end{array}$ & $\begin{array}{l}\text { Kesim } \\
\text { Öncesi }\end{array}$ \\
\hline Metebolik enerji kcal/kg & 3.09 & 3.18 & 3.25 & 3.28 \\
\hline Kuru madde, (\%) & 90.2 & 90.3 & 90.3 & 90.4 \\
\hline Ham protein, (\%) & 23.8 & 20.8 & 20.0 & 19.0 \\
\hline Ham kül, (\%) & 6.50 & 6.25 & 6.30 & 7.10 \\
\hline Calsiyum, (\%) & 0.95 & 0.95 & 0.90 & 0.90 \\
\hline Fosfor, (\%) & 0.66 & 0.65 & 0.63 & 0.63 \\
\hline Yararlanılabilir fosfor, $(\%)$ & 0.43 & 0.43 & 0.43 & 0.43 \\
\hline $\mathrm{Na},(\%)$ & 0.14 & 0.14 & 0.14 & 0.15 \\
\hline Ham yağ, (\%) & 8.00 & 9.00 & 9.60 & 10.0 \\
\hline Ham sellüloz, (\%) & 3.25 & 3.44 & 3.25 & 3.25 \\
\hline
\end{tabular}

Objektif pelet kalite kriterleri (D, TY, NI) ASAE., (1983) tarafından bildirilen yöntemlerle, subjektif kalite kriterleri de (tat, koku, renk, şekil, boy ve peletin dış yüzey pürüzsüzlüğü ve homojenliği) Payne ve ark. (1994) tarafindan bildirildiği şekilde yapılmıştır.

Araştırma sonuçlanın istatistiki değerlendirilmesi tesadüf parselleri deneme düzeninde varyans analizi metodu, guruplar arasındaki istatistiki farklılıklarının tespitinde ise Duncan Çoklu Karşılaştırma Testi uygulanmıştır (Düzgüneş ve ark. 1987). Araştırma süresince ölen civcivlere ait sayıların guruplara göre istatistiki kontrolünde yine Düzgüneş ve ark., (1987) tarafindan bildirilen Khi-Kare metodu kullanılmıştır.

\section{Bulgular ve Tartışma}

\subsection{Broyler performans bulguları}

Araştırmada elde edilen CA, CAA, YT, YDS sayısına ait veriler tablo 3.1'de verilmiştir.

Canlı ağırlık ortalaması bakımından guruplar arasında varyans analizi sonucuna göre önemli bir farklılık tespit edilememiştir $(\mathrm{P}>0.05)$. Gruplar arasındaki farklılıklar CA bakımından 3.0ve 4. haftalar da istatistik olarak önemli çıkmıştır ( $\mathrm{p}<0.05$ ). Gurupların besi sonu CA ortalamaları sırasıyla 1924.0, 2077.5, 1988.1 ve 2026.3 olarak bulunmuştur.

Canlı ağırlık artış ortalaması bakımından da gruplar arasında istatistiki önemli bir farklılık tespit edilememiştir $(\mathrm{P}>0.05)$. Gruplar arasındaki CAA bakımından farklılıklar ise 0-2. ve 0-4. haftalarda istatistik olarak önemli çıkmıştır $(\mathrm{p}<0.05)$. Grupların CAA ortalamaları 0-6 hafta da sırasıyla 1883.7, 2037.7, 1947.7 ve 1986.0' dir.

Yem tüketimi bakımından da yine varyans analizi sonucuna göre guruplar arasında önemli bir farklılık tespit edilememiştir ( $\mathrm{P}>0.05)$. Gurupların besi sonu YT ile ilgili veriler ise sırasıyla 3328.1, 3390.3, 3188.2 ve 3131.0 olarak ölçülmüştür.

Yem değerlendirme sayıları bakımından ise 0-6. hafta itibari ile gruplar arasındaki fark istatistiki olarak önemli çıkmıştır $(\mathrm{p}<0.05)$. Bu dönem bakımından grupların YDS ait ortalamalar ise sırasıyla 1.77, 1.66, 1.64 ve 1.58 olarak tespit edilmiştir. 
Tablo 3.1. Araştırma guruplarına ait performans değerleri

\begin{tabular}{|c|c|c|c|c|c|c|c|c|}
\hline \multirow{3}{*}{ GURUPLAR } & \multicolumn{8}{|c|}{ HAFTALAR } \\
\hline & \multicolumn{4}{|c|}{ Canlı ağırlık (CA) } & \multicolumn{4}{|c|}{ Canlı ağırlık artışı(CAA) } \\
\hline & $\begin{array}{c}1 . \\
\text { Başlangıç }\end{array}$ & $\begin{array}{c}3 . \\
\text { Hafta }\end{array}$ & $\begin{array}{c}4 . \\
\text { Hafta }\end{array}$ & $\begin{array}{c}6 . \\
\text { Hafta }\end{array}$ & $\begin{array}{c}0-2 \\
\text { Hafta }\end{array}$ & $\begin{array}{c}2-4 \\
\text { Hafta }\end{array}$ & $\begin{array}{c}4-6 \\
\text { Hafta }\end{array}$ & $\begin{array}{c}0-6 \\
\text { Hafta }\end{array}$ \\
\hline 1. Gurup* & 40.39 & $590.33^{\mathrm{b}}$ & $930.91^{\mathrm{b}}$ & 1924.0 & $239.84^{\mathrm{b}}$ & $650.70^{\mathrm{b}}$ & 993.1 & 1883.7 \\
\hline 2. Gurup* & 40.13 & $666.05^{\mathrm{a}}$ & $1019.4^{\mathrm{a}}$ & 2077.5 & $267.94^{b}$ & $711.37^{\mathrm{ab}}$ & 1058.0 & 2037.7 \\
\hline 3. Gurup* & 40.35 & $623.49^{\mathrm{ab}}$ & $982.7^{\mathrm{ab}}$ & 1988.1 & $238.45^{b}$ & $703.87^{\mathrm{ab}}$ & 1005.0 & 1947.7 \\
\hline 4. Gurup* & 40.30 & $634.56^{\mathrm{ab}}$ & $1039.3^{\mathrm{a}}$ & 2026.3 & $257.64^{\mathrm{ab}}$ & $741.38^{\mathrm{a}}$ & 987.0 & 1986.0 \\
\hline $\mathbf{P}$ & 0.881 & 0.016 & 0.033 & 0.331 & $\mathbf{0 . 0 3 7}$ & 0.051 & 0.706 & 0.330 \\
\hline
\end{tabular}

${ }_{a, b} \mathbf{b}$ Ann sütunda üstleri farklı harf taşıyan guruplar arasındaki farklılıklar istatistik] olarak önemlidir $(\mathbf{p}<0.05)$

\begin{tabular}{|l|c|c|c|c|c|c|c|c|}
\hline \multirow{2}{*}{ GURUPLAR } & \multicolumn{4}{|c|}{ Yem tüketimi (YT) } & \multicolumn{3}{c|}{ Yem değerlendirme sayısı (YDS) } \\
\cline { 2 - 10 } & $\begin{array}{c}\mathbf{0 - 2} \\
\text { Hafta }\end{array}$ & $\begin{array}{c}\mathbf{2 - 4} \\
\text { Hafta }\end{array}$ & $\begin{array}{c}\mathbf{4 - 6} \\
\text { Hafta }\end{array}$ & $\begin{array}{c}\mathbf{0 - 6} \\
\text { Hafta }\end{array}$ & $\begin{array}{c}\mathbf{0 - 2} \\
\text { Hafta }\end{array}$ & $\begin{array}{c}\mathbf{2 - 4} \\
\text { Hafta }\end{array}$ & $\begin{array}{c}\text { 4-6 } \\
\text { Hafta }\end{array}$ & $\begin{array}{c}\mathbf{0 - 6} \\
\text { Hafta }\end{array}$ \\
\hline 1. Gurup* & 340.85 & 1327.4 & 1418.8 & 3328 & 1.42 & 2.04 & 1.43 & $1.77^{\mathrm{a}}$ \\
\hline 2. Gurup* & 349.21 & 1398.0 & 1491.5 & 3390 & 1.30 & 1.97 & 1.41 & $1,66^{\mathrm{b}}$ \\
\hline 3. Gurup* & 314.86 & 1322.4 & 1414.7 & 3188 & 1.32 & 1.88 & 1.41 & $1,64^{\mathrm{b}}$ \\
\hline 4. Gurup* & 347.91 & 1373.4 & 1461.4 & 3131 & 1.36 & 1.86 & 1.48 & $1,58^{\mathrm{b}}$ \\
\hline P & 0.203 & 0.342 & 0.344 & 0.108 & 0.037 & 0,051 & 0.706, & 0.330 \\
\hline
\end{tabular}

a,b Aynı sütunda üstleri farklı harf taşıyan guruplar arasındaki farklılıklar istatistiki olarak önemlidir $(\mathrm{p}<0.05)$

*1. GURUP; Toz yem grubu (Kontrol), 2. GURUP; Buharala yapilan pelet yem grubu, 3. GURUP; LignoBond bağlayıcısı içerikli pelet yem grubu, 4. GURUP; Aquacube bağlayıcısı içerikli pelet yem grubu.

\section{2. Ölüm oranlarına ait bulgular}

Deneme sonu itibariyle guruplarda toplam 9 hayvan ölmüştür, ölümlerin guruplara göre dağılımı sırasıyla 2, 2, 3, 2' dir. Guruplarda ölüm oranları arasındaki farklılıklar istatistiki olarak önemli bulunmamıştır.

\subsection{Pelet kalite kriterlerine ait bulgular}

\subsubsection{Objektif kalite kriter bulguları}

Pelet yem guruplarında tespit edilen objektif kalite kriterlerine ait (D; (dayanıklılık), NI; (nem içeriği), ve TY; (toz yem)) yüzdesine ait ortalama değerler tablo 3.2.'de verilmiștir.

Elde edilen verilere göre dönem sonu itibariyle pelet yem guruplarına ait veriler sirasiyla "D" bakımından \%79.8, \% 87.7 ve $\% 88.9$, "TY" yüzdesi için $\% 16.8, \% 15.2$ ve $\% 14.8$ ve bir diğer önemli kriter olan yüzde "Nİ" de \% 10.9, \%10.6, \%11.2 ve \%11.4 bulunmuştur.

Tablo 3.2. Pelet yem guruplarının objektif kalite kriterlerine ait sonuçlar

\begin{tabular}{|c|c|c|c|c|c|c|c|c|c|c|c|c|}
\hline \multirow{4}{*}{$\begin{array}{l}\text { YAŞ } \\
\text { DÖNEMI }\end{array}$} & \multicolumn{12}{|c|}{ GRUPLAR } \\
\hline & \multicolumn{3}{|c|}{ 1. GURUP* } & \multicolumn{3}{|c|}{ 2. GURUP* } & \multicolumn{3}{|c|}{ 3. GURUP ${ }^{*}$} & \multicolumn{3}{|c|}{ 4. GURUP* } \\
\hline & $D^{* * *}$ & $T Y * *$ & $\mathrm{Nl}^{* * *}$ & D & TY & Ni & D & TY & Ni & D & TY & Ni \\
\hline & $(\%)$ & $(\%)$ & (\%) & (\%) & $(\%)$ & (\%) & $(\%)$ & (\%) & $(\%)$ & $(\%)$ & (\%) & (\%) \\
\hline 0-2 Hafta & - & - & 10.2 & - & - & 11.0 & - & - & 11.5 & - & & 11.6 \\
\hline 2-4 Hafta & - & - & 10.9 & 84.8 & 16.9 & 11.1 & 89.9 & 17.2 & 11.6 & 91.3 & 16.2 & 11.2 \\
\hline 4-6 Hafta & - & - & 10.4 & 85.6 & 17.4 & 10.6 & 87.7 & 15.6 & 11.5 & 89.6 & 13.7 & 11.6 \\
\hline 0-6 Hafta & - & - & 10.6 & 79.8 & 16.8 & 10.9 & 87.7 & 15.2 & 11.2 & 88.9 & 14.8 & 11.4 \\
\hline
\end{tabular}

*1. GURUP; Toz yem grubu (Kontrol), 2. GURUP; Buharala yapılan pelet yem grubu, 3. GURUP; LignoBond bağlayıcısı içerikli pelet yem grubu, 4. GURUP; Aquacube bağlayıcısı içerikli pelet yem grubu

** D: Dayanıklık; TY: Toz yem; Nİ: Nem İçeriği 


\subsubsection{Subjektif kalite kriter bulguları}

Araştırmada pelet yemlerin sübjektif kalite kriteri olan tat ve koku bakımından 3 pelet yem grubunda da dönemler itibariyle hiçbir farkllık görülmemiştir.

Renk bakımından da buharla muamele edilen guruplardaki peletlerin rengi bejden acık sarıya doğru daha matlaşan bir renk görülürken, bağlayıcı içeren gruplarda daha parlak sarı renk tonları tespit edilmiştir.

Şekil ve boy üniformitesi bakımından ise 3. ve 4. dönemlerde bağlayıcı içeren gruplarda homojenlik acısından daha iyi sonuçlar elde edilmiştir.

Pelet yüzeylerindeki pürüzsüzlük ve homojenlik bakımından da ise her dönemde yine pelet bağlayıcıları içeren guruplarda daha iyi sonuçlar saptanmıştır.

\subsubsection{Karma yemler ve broyler performansı arasındaki ilişkiye ait bulgular}

Denem sonunda (kesim öncesi) broylerlerden elde edilen CA, CAA, YT, YDS gibi performans değerleri ve objektif pelet kalite kriterleri tablo 3.3' de özetlenmiştir. Bu çizelgeden anlaşılacağı gibi besi sonunda peletlemenin ve pelet bağlayıcılarının YDS üzerine etkisi olumlu olmuştur $(\mathrm{P}<0.05)$. Objektif Pelet kalitesi bakımından pelet bağlayıcılarının kullanılması pelet kalitesini olumlu yönde arttırmıştır ve pelet kalite kriterleri bakımından bağlayıcı içeren guruplarda D, TY ve Nİ değerleri bakımından en iyi sonuçlar elde edilmiştir.

Tablo 3.3. Dönem Sonu itibariyle broyler performans değerleri ve pelet kalite kriterleri

\begin{tabular}{|c|c|c|c|c|c|c|c|}
\hline \multirow{2}{*}{ Guruplar } & \multicolumn{4}{|c|}{ Broyler performans değerleri (0-6 hafta) } & \multicolumn{3}{|c|}{ Pelet kalite kriterleri (0-6 hafta) } \\
\hline & $\mathbf{C A}^{1}$ & $\mathrm{CAA}^{2}$ & $\mathbf{Y T}^{3}$ & YDS $^{4}$ & $D^{5}(\%)$ & TY ${ }^{6}(\%)$ & $\mathbf{N I} \dot{I}^{7}(\%)$ \\
\hline 1.Gurup* & 1924.0 & 1883.7 & 3328 & $1.75^{\mathrm{a}}$ & - & - & 10.6 \\
\hline 2.Gurup* & 2077.5 & 2037.3 & 3390 & $1.66^{\mathrm{b}}$ & 79.8 & 16.8 & 10.9 \\
\hline 3.Gurup* & 1988.1 & 1947.3 & 3188 & $1.63^{b}$ & 87.7 & 15.7 & 11.2 \\
\hline 4.Gurup* & 2026.3 & 1986.0 & 3131 & $1.57^{\mathrm{b}}$ & 88.9 & 14.8 & 11.4 \\
\hline $\mathbf{P}$ & 0.331 & 0.330 & 0.108 & 0.330 & & & \\
\hline
\end{tabular}

a,b Aynı sütunda üstleri farklı harf taşıyan guruplar arasındaki farklılıklar istatistiki olarak önemlidir $(\mathbf{p}<0.05)$

1 Canlı Ağırlık; ${ }^{2}$ Canlı Ağırlık Artışı; ${ }^{3}$ Yem Tüketimi; ${ }^{4}$ Yem Değerlendirme Sayısı; ${ }^{5}$ Dayanıklılık; ${ }^{6}$ Toz Yem; ${ }^{7}$ Nem Içeriği

*1.GURUP; Toz yem grubu (Kontrol), 2. GURUP; Buharala yapilan pelet yem grubu, 3. GURUP; LignoBond bağlayıcis1 içerikli pelet yem grubu, 4. GURUP; Aquacube bağlayıcısı içerikli pelet yem grubu

\section{Tartışma}

Deneme sonu itibariyle peletenmiş yem tüketen grupların CA ve CAA ortalama değerleri rakamsal olarak toz yem (kontrol) grubundan daha yüksektir. Ancak gruplar arsındaki bu farklılıklar istatistiki olarak önemli bulunmamıştır ( $\mathrm{p}>0.05$ ). Bu sonuç Zang ve ark., 2009, Mirghelenj ve Golian, (2009) tarafından bildirilen broyler yemlerinin peletlemesinin CA, CAA ve YT olumlu yönde etkiler şeklindeki bildirişleriyle uyumsuzken, Acar ve ark., (1991), McAllister ve ark., (2000), Galobart ve Morant, (2005) ve Salari ve ark., (2006)'nın karma yem formunun broylerlerde yem tüketimi ve canlı ağırlık üzerine etkisi olmadığına dair sonuçlarıyla uyumludur. Bununla birlikte pelet yem gruplarının 3. ve 4. hafta CA, 0-2. ve 2-4. haftada da CAA ortalaması kontrol grubundan daha yüksektir $(\mathrm{p}<0.05)$. Bu haftalar itibariyle de grupların CA ve CAA ortalamaları yemin fiziki formundan olumlu etkilenmiştir ve bu veriler, broylerlerin farklı büyüme dönemlerde CA ve CAA olumlu yönde etkileme olasılığını ortaya koyan diğer çalışmaların sonuçlarıyla paraleldir (Callet, 1965; Zatari ve Sell, 1990; Ensminger ve ark., 1990; Pettersson ve ark., 1991; Nir ve ark., 1994ab; Siddıquie ve ark., 1994; Chewning ve ark., 2012; Mingbin ve ark., 2015). Ancak bu sonuçlara dayanarak peletlemenin CA ve CAA etkileyeceği konusunda kesin bir yargıya varmak mümkün olmamaktadır.

Yem tüketimi bakımından da guruplar arasında arasındaki farkların hiçbir dönem itibariyle istatistiki olarak önem taşımadığı görülmektedir ( $\mathrm{P}>0.05)$. Bu bulgular yine Acar ve ark., (1991), Salari ve ark., (2006) ve Sogunle ve ark., (2013)'nın bildirişleri ile örtüşmekte, ancak bu araştırma sonucunda, peletlemenin yem tüketimini arttırılmasına ilişkin hipotezlerin aksine bir sonuç elde edilmiştir (Ergül, (1975); Reddy ve Narahari, (1993); Nir ve ark., 1994a,b; Payne ve ark., 19941; Lieberet, 1995; Lacassagne, 1998; Dozier ve ark., 2010; McKinney ve Teeter, 2004; Chewning ve ark., 2012).

Yem değerlendirme sayısı için yapılan varyans analizi sonucunda ise 6. hafta itibariyle pelet yem gruplarının hepsinde toz yem tüketen guruptan daha iyi veriler bulunmuştur ve sonuçlar istatistiki olarakta önemlidir $(\mathrm{p}<0.05)$. Bu veriler peletleme işleminin YDS'nı olumlu etkiler şeklindeki benzer araştırma sonuçlarını destekler niteliktedir (Ergül 1975; Reddy ve Narahari 1993; Nir ve ark., 1994a,b; Lieberet, 1995; Payne ve ark., 1996; Lacassagne, 1998; McKinney and Teeter, 2004; Amerah ve ark.,

64 | P a g e 
2008; Mirghelenj ve Golian 2009; Mohammad ve ark., 1919a).

Pelet yem grupları arasında bağlayıcı içeren gruplardan elde edilen veriler istatistiki olarak önemsiz olmakla birlikte, pelet bağlayıcılar YDS bakımından 0.19 ve 0.13 'lük iyileşme sağlar şeklindeki literatür bildirişlerindeki bazı değerlere yakın, bazı değerlerden de yüksek çıkmıştır (Salmon, 1985; Elliot ve Edwards 1991).

Araştırma da yemleme esnasında yapılan gözlemler sonucunda ise pelet yem tüketen gurupların yemi daha kısa zamanda yedikleri ve daha az hareket halinde oldukları tespit edilmiştir. Bu izlenim pelet yemle beslenen broylerlerin daha az enerji harcadığı ve arta kalan enerjinin performansa yansıtıldığ 1 şeklindeki görüşleri doğrular niteliktedir (Acar ve ark., 1991; Payne, 1996). Ancak gerek bizim çalışmamızdaki gerekse diğer araştırmalardaki bu tür gözlemler subjektif olarak nitelenebileceğinden bu tür gözlemlerin sayısal ölçümlere dayandırılması daha güvenilir sonuçlar elde edilmesini sağlayabilir.

Pelet kalite analiz sonuçlarına göre elde edilen veriler, bağlayıcıların pelet kalitesini arttırır şeklindeki bildirişlerle uyumlu verilerdir (Calet, 1965; Kivimae, 1978; Acar ve ark. 1991; Corey ve ark., 2014; Attar ve ark., 2018; Mohammad ve ark., 2019b). Şöyleki bu araştırmada pelet bağlayıcları içeren gruplardan elde edilen pelet kalite kriteri olan D`a ait verilerindeki artışa paralel olarak YDS ‘nda da iyileşme olmuştur ve bu Corey ve ark., (2014) ve Wamsley ve ark., (2014) tarafindan elde edilen sonuçlarla uyumludur. Ayrıca gruplar arasında dayanıklılık açısından tespit edilen \%10' luk artış da Angualo ve ark. (1995)' nın araştırmalarında bildirilen oranlarla aynı, Payne, (1994) tarafından bildirilen değerlerden daha yüksek çıkmıştır.

Pelet Nİ yüzdesi bakımından da pelet bağlayıcıları içeren guruplarda \% $0.5^{\prime}$ lik sağlanan bir iyileşme de Castaldo ve Clayton, (1995)' de verilen Nİ yüzdesi ile benzer sonuçlardır.

$\mathrm{Bu}$ araştırma sonucunda elde edilen veriler bağlayıcıların pelet kalitesini artırdığına dair ileri sürülen hipotezlerle uyumluluk içerisinedir (Kivimea, 1978; Hopf ve ark., 1994; Corey ve ark., 2014; Attar ve ark., 2018; Mohammad ve ark., 2019b). Pelet kalitesindeki artışa paralel olarak pelet yemin D`` artmış, buna paralel yüzde TY ve Nİ olumlu etkilenmiştir. Bağlayıcı içeren guruplarda Nİ yüzdelerindeki artışa paralel pelet D' ında da artış sağlaması, pelet bağlayıcılarının yem içerisindeki nem oranını arttırıp, hammadelerin daha iyi yapışmasını sağlar şeklindeki görüşleri destekler nitelikte sonuçlardır (Castaldo ve Clayton, 1995; Angulo ve ark., 1995). Bağlayıcı kullanılan pelet yemlerde, D ile birlikte yüzde nem içeriğinin artması, peletlerde TY oranını azaltmıştır. Pelet dayanıklılığında tespit edilen değerler yine Angulo ve ark., (1995)'nın sonuçlarıyla örtüşmekte ve diğer bazı araştırma sonuçları ile de benzerlik göstermektedir (Kivimea, 1978; Payne, 1994; Hopf ve ark., 1994). Pelet bağlayıcıları kullanılan yemlerde, objektif kalite kriterleriyle birlikte sübjektif kalite kriterleride artmıştır. Aynı zamanda artan pelet kalitesine paralel YDS' ında da artış sağlanması pelet kalitesi ile yem değerlendirme arasında pozitif bir ilişki olduğunu savunan araştırma sonuçları ile benzerlik göstermektedir (Acar ve ark., 1991; Elliot ve Edwards, 1991; Laboa, 1993; Ergül, 1994; McKinney ve Teeter, 2004; Chewning ve ark., 2012; Mohammad ve ark., 1919a).

Sonuç olarak, karma yemin fiziki formunun broylerlerde yemden yararlanmayı ve peletlemede kullanılan bağlayıcıların da objektif ve sübjektif pelet kalitesini etkilediği tespit edilmiştir. Bu araştırmanın sonucuna göre bağlayıcıların pelet kalitesini ve yemden yararlanmayı iyileştirmede kullanılabileceği, ancak her karma yem üreticisinin kendi teknolojisine, kullandığı ham maddeye uygun bağlayıcıyı seçmesi ve dozunu iyi ayarlaması gerektiğini düşündürmektedir.

\section{Sonuç}

Broyler karma yemlerinin peletlenmesin de bazı pelet bağlayıcılarının pelet kalitesine ve broyler performansına etkilerinin incelendiği bu araştırmada elde edilen performans değerlerine ve pelet kalite analizlerine göre şu sonuçlara ulaşılmıştır.

1- Karma yemin fiziki formu Broylerlerin YDS' nı önemli derecede etkilemiştir. Ancak peletleme işleminin broylerlerde YDS üzerine olumlu etkisi olurken, besi sonu CA, CAA ve YT üzerine ise önemli bir etkisinin olmadığı tespit edilmiştir. Bununla birlikte pelet bağlayıcıların YDS üzerine farklı bir etkisi de bulunmamıştır.

2- Ancak bu çalışmada kullanılan iki farklı pelet bağlayıcının (LignoBond ve Aquacube) objektif ve subjektif pelet kalitesini olumlu yönde etkilediği belirlenmiştir. Pelet bağlayıcısı kullanımı ile peletin objektif kalite kriterleri olarak D, TY ve Nİ yüzdelerini ve subjektif kalite kriterleri olarak da şekil, boy, pürüsüzlük ve homojenite oranı olumlu etkilenmiştir.

3- $\mathrm{Bu}$ sonuçlara paralel olarak yem kalitesi ve YDS arasında pozitif bir ilişki ortaya çıkmıştır. Peletleme işleminin broylerlerde YDS arttırdığı ve pelet bağlayıcılarının da pelet kalite kriterlerini arttırdığı söylenebilir. Ancak bu çalışmada elde edilen verilere benzer araştırma sonuçları olduğu gibi bu çalışmanın verilerini desteklemeyen araştırma sonuçlarının da bulunması konu ile ilgili daha detaylı 
çalışmaların yapılmasının peletlemenin ve bağlayıcıların broyler performansı üzerine etkilerinin netleşmesine katkıda bulunacaktır.

\section{Kaynaklar}

Acar, N., Moran, E. T., Revington, W. H., Bilgili, S. F., 1991. Effect of improved pellet quality from using a calcium lignosulfonate binder of performance and carcass yield of broylers reared ljnder diffiferent. Mârketing schemes. Poultry Science.:70:6. 1331-1344.

Allred, J. B., Fry, R. E., Jensen. L. S., Megiines, J., 1957. Studies with chickens on provment in nutritive value of feed ingredients by pelleting. Poultry Science.: 36: 1284-1289.

Akyıldız, A. R., 1984.Yemler Bilgisi Lab. Kılavuzu Ank. Üni. Ziraat Fak. Yay. 895. Uyg. Kılavuzu 213. Ankara.

Amerah A. M., Ravindran, V., Lentle, R. G., Thomas, D. G., 2008. Influence of feed particle size on the performance, energy utilization, digestive tract development, and digesta parameters of broiler starters fed wheat- and corn-based diets. Poult Sci.: 87:2320-2328.

Angulo, E., Brufau. E., Esteve, J. E.,1995. Effect of sepioüte on pellet durabuty in feeds differing in fat and fibre content. Ani. Feed Sci. Technology.: 53:3, 233-241.

Arash Moradi, Soudabeh Moradi, Reza Abdollahi, M., 2018. Influence of feed.ingredients with pelletbinding properties on physical pellet quality, growth performance, carcass characteristics and nutrient retention in broiler chickens. Animal Production Sci.: 59(1) 73-81. doi.org/10.1071/AN17109.

Attar, A., Kermanshahi, H., Golian A., 2018. Effects of conditioning time and sodium b entonite on pellet quality, growth performance, intestinal morphology and nutrient retention in finisher broilers.Br Poult Sci.: 59(2):190-197. doi: 10.1080/00071668.2017.1409422.

Basmacioğlu, H., 2004. Karma Yem Üretiminde Pelet Ka litesine Etki Eden Etkenler. Hayvansal Üretim.: 45(1): 23-30.

Behnke, K. C., 1996. Feed manufacturing technology:Current issues and challenges. Anim. Feed Sci. Technol.: 62:49-57.

Behnke, K. C., Beyer, R. S., 2002. Effect of feed processing on broiler performance. VIII International Seminar on Poultry Production and Pathology. Santiago, Chile.

Briggs, J.L., Maier, D.E., Watkins, B.A., Behnke, K.C., 1999. Effect of ingredients and processing parameters on pellet quality. Poult. Sci.: 78:1464-1471.

Calet, C., 1965. The relative value of pellets versus mash and grain in poultry. World Poultry Sicence Journal: 21: 23-52.

Castaing, J., 1990. Effect of using the Sepiolit exal in relation to crude fibre and fat contents of feed for fattening an France. 26: 159-205.

Castaldo, DJ., Clayton, G., 1995. High output pelletting. Feed International. July; 24-28.

Chewning, C. G., Stark C. R., Brake, J., 2012. Effects of particle size and feed form on broiler performance. J. Appl Poult Res; 21:830-7.

Corey, A. M., Wamsley, K. G. S., Winowiski, T. S., Moritz, J. S., 2014. Effects of calcium lignosulfonate, mixer-added fat, and feed form on feed manufacture and broiler performance. J. Appl. Poult. Res. 23:418-428. 
Cox, N., Burdıck, J. S., Bailey, J. E., 1986. Effect of the stcam conditoninig and pelleting procces on the microbiology and quality of comerical type poultry feeds. Poultry Science. 65: 704-709.

Das, H. K., Hattula, M. T., Myllymali, O. M., Malki, Y., 1993. Effects of formülation on processing variables on dry fish feed pellet containing fish waste. Journal of The Science of Food and Agriculture. 61:2, 181-187.

Doğan, K.,1993. Kümes Hay. Beslenmesi. Ank. Üni. Ziraat Fakültesi Yayınları 1290. Ders Kitabı 368. Ankara.

Dozier, III. W. A., Behnke K. C., Gehring C. K., Branton S. L., 2010. Effects of feed form on growth performance and processing yields of broiler chickens during a 42-day pro-duction period. J Appl Poult Res;19:219-26.

Düzgüneş, O., Kesici, T., 1987. Kavuncu, O. ve Gürbüz, F. Araştırma deneme metodları ders kitabı. Zir. Fak. Yayınları, 1021, 295-381. Ankara.

Ergül, M., 1994. Karma Yem Teknolojisi. E. Ü. Ziraat Fak. Yay. Ders kitabı. İzmir. Elliot, M., Edvvards, H. M., 1991. Comparison of the effects of synthetic and natural zeolite on bying hens and broiler chicken performance. Poultry Sci. 70: 2115-2130.

Ensminger, E. N., Oldfiel., J. E., Heinemann, W. W., 1990. Feeds suplements pelet binders. Feeds Nutrition. 5:523-546.

Galobart, J., Morant, E.T., 2005. Influence of stocking density and feed pellet quality on heat stressed broilers from 6 to 8 weeks of age. Int J Poult Sci, 4, pp. 55-59It.

Hopf, M., Vorher, K. F., 1994. Use of liquid pelleting aids. Muhle mischfuttertechnik.131: 3,21- 24

Hott, J. M., Buchanan, N. P., Cutlip, S. E, Moritz, J. S., 2008. The effect of moisture addition with a mold inhibitor on pellet quality, feed manufacture, and broiler performance. J. Appl. Poult. Res. $17: 262-271$.

Jahan, M.S., Asaduzzaman, M., Sarkar, A.K., 2006. Performance of broiler fed on mash, pellet and crumble. Int J Poult Sci ;5:265-270.

Jensen, L. S., Merrill, L. H. Reddy, C. V., McGinnis, J., 1962. Observations on eating patterns and rate of food passage of birds fed pelleted and unpelleted diets. Poult. Sci. 41:1414-1419.

Keysuke Muramatsu, Andréia Massuquetto, Fabiano Dahlke, Alex Maiorka, 2015. Factors that Affect Pellet Quality: A Review. Journal of Agricultural Science and Technology.: A.5: P: 717-722 .doi: 10.17265/2161-6256/2015.09.002.

Kivimae, A., 1978. Effects of lignosulfhonate on poultry when used as a binder in compounded feed. Arch. Geflugelkd. 42: 238-245.

Laboa, U. L., Pazinatto, A. C., Roverso, E. A., Margues, L., Hortericio, E., 1993. Evaluation of the efficiency of binding agents in feeds for shrimps. Bulletin do İnstitutü Pesca. 20: 87-94.

Lacassagne, L., Francesch, M., Carre, B., Melicon, J. D., 1998. Utalization of tann conteining and tanan free faba beans by young chickens effect of pelleting feeds on energy protein and starch digestibility. Animal Feed Science and Technology. 20:1, 59-68.

Lemme, A., P., Wijtten, J. A., Michen, J., Petri, A., Langhout, D. J., 2006. Responses of male growing broil- ers to increasing levels of balanced protein offered as coarse mash or pellets of varying quality. Poult. Sci.: 85:721-730. 
Lieberet, F., 1995. Feed procesing and energy reduction in broiler feed. Muhle mischfuttertechnik. 132:18, 288-290.

McAllister, A., McCracken, K. J., Magee, F .A., 2000. Influence of grinding, rolling and pelleting on thenutritional value of grain sorghums and yellow cornfor broilers. World's Poult. Sci. J., 56: $215-222$

McKinney L. J., Teeter R. G., 2004. Predicting effective caloric value of nonnutritive factors: I. Pellet quality and II. Prediction of consequential formulation dead zones. Poult Sci;83:1165-1174.

Mcintosh, J. I., Silnger, S. J., Sibbald, I. R. and Ashton, G. C., 1962. Factors effecting the metabolizable energy content of poultry feeds. Poultry Science.41:445-456.

Mingbin, Lv, Lei Yann, Zhengguo, Wang, Sha An, Miaomiao Wu, Zunzhou Lv, 2015. Animal Nutrition. Volume 1, Issue 3, Pages 252-256. ttps://doi.org/10.1016/j.aninu.2015.06.001.

Mirghelenj, S.A., Golian, A., 2009. Effects of feed form on development of digestive tract, performance and carcass traits of broiler chickens. J Anim Vet Adv, 8, pp. 1911-1915.

Mohammadi Ghasem Abadi M. H., Moravej H., Shivazad, Karimi, M., Torshizi, M.A., Kim, W. K., 2019a. Effects of feed form and particle size, and pellet binder on performance, digestive tract parameters, intestinal morphology, and cecal microflora populations in broilers. Poult Sci.: 1;98(3):1432-1440. doi: $10.3382 / \mathrm{ps} / \mathrm{pey} 488$.

Mohammad, Hossein Mohammadi Ghasem Abadi, Hossein Moravej, Mahmoud Shivazad, Mohammad Amir Karimi Torshizi, Woo Kyun Kim, 2019b. Effect of different types and levels of fat addition and pellet binders on physical pellet quality of broiler feeds. Poult Sci.: 98(10): 47454754. doi: $10.3382 / \mathrm{ps} / \mathrm{pez} 190$.

Moradi, A., Moradi, S., Abdollahi, M. R., 2019. Influence of feed ingredients with pellet-binding properties on physical pellet quality, growth performance, carcass characteristics and nutrient retention in broiler chickens. Anim. Prod. Sci.: 59:73-81.

Moran, E. T., 1989. Effect of pellet quality on the performance of meat birds. Animal Nutrition. 8708. Londan.

Moritz, J. S. Beyer, R.S., Wilson, K.J., Cramer, K.R., Mckinney, L.J., and Fairchild, F.J., 2001. Effect of Moisture Addition at the Mixer to a Corn-Soybean-Based Diet on Broiler Performance. J. Appl. Poult. Res.10: 347-353.

Moritz, J. S., Cramer, K. R., Wilson, K. J., Beyer., R. S., 2003. Feed manufacture and feeding of rations with graded levels of added moisture formulated to different energy densities. J. Appl. Poult. Res. 12:371-381.

Nauman, C., Bassler, R., 1976. Diechemische unter suhing von futtermitteln. Metodenbuch band. İII.

Neves, D. P., Banhazi, T. M., Nääs, I. A., 2014, Feeding behaviour of broiler chickens: a review on the biomechanical characteristics. Rev. Bras. Cienc. Avic.: vol.16, no.2 Campinas. doi.org/10.1590/1516-635x16021-16.

Nir, I., Melcion, J. P., Picard, M., 1990. Effect of particle size of sorgum grains on feed intake and performance yang broylers. Poultry Science. 69: 2177-2184.

Nir, I., Shefet, G., Aroni, Y., 1994a. Effect of particle size of maize grains on feed intake and performance yang broylers. Poultry Science. 73: 45-43.

Nir, I., Twina, Y., Grosman, E., Nitsan, Z., 1994b. Qantitative Effects of pelleting performance, gastrointestinaltract an behaveur of meat type chickens. Biritish Poultry Science. 35:4, 589-602. 
NRC, 1994, Nutrient Requirements of Poultry. National Research Council. Committee on Poultry Nutrition Committee on Animal Nutrition.Ninth Revised Edition. Washington, D.C.

Payne, J., Ratrik, W., Smith, T. Winowiski, T., 1994. Quantitive effecet of pelleting on performance gastrointestinal tract an behavaurof meat type chikens.British Poultry Science. 35: 4. 589- 602.

Payne, J., 1996. Prodiction and guality of pelleted poultry feed. Zootecnica Intemational. 19: 3. 53- 59.

Pejin, G., Supic, B., 1989. Effect of pelleted feed on the fattening autcome and meat quality of broilers. Zbomik. Radova Institü Za Staccarstuo. Novi Sad. 19: 20. 319-323.

Pettersson, O., Greham, H., Aman, P., 1991. The Nutritive value for broyler chickens of pelleting and enzyme suplementtation of diet containing broiler, wheat and rye. Animal Feed Scence and Technology., 33: 1-2, 1-14.

Preston, C. M., McCracken, K. J., McAllister, A., 2000. Effect of diet form and enzyme supplementation on growth, efficiency and energy utilisation of wheat-based diets for broilers. $\mathrm{Br}$ Poult Sci., 41, pp. 324-331.

Proudfoot, F. G., Hulan, H. W., DeWitt, W.F., 1979. Effects of using 0, 1.0, 1.5, and 2.0\% 'Lignosol FG'as a pellet binder in broiler chick finisher diets. Poult. Sci.: 58:87-89.

Reace, F.N., Loot, B.D., Deaton, J.w., 1986. The effevts of hammer mill screen size on ground corn particle size pellet durability and broiler performans. Poultry Sci.: 65:7, 1257-1261.

Reddy, S., Narahri, P., 1993. ffect of dieary energy level and peelleting of feed on the performance of broiler cihckns in tropic İndian Journal of AnimalScience. 63:4, 478-480.

Salari, S., Kermanshahi, H., Nasiri, M. H., 2006. Effect of sodium bentonite and comparison of pellet vs. mash on performance of broiler chickens. Int J Poult Sci, 5, pp. 31-34.

Salmon, R.E., 1985. Effect of pelleting added Sodium Bentonite and fat in a wheat based diet on performance and carcass characteristich of smoll white turkeys. Animal Feed Science And Technology. 12: 3,223-232.

Siddıquie, A., Harbi, A. L., Najada, A. R., 1994. Durability water absorption and theirevaluation as tilapia feeds in Saudi Arabia Arab Gulf Jurnal Of Scientific Reserch. 12:3. 581-594.

Sibbald, I.R. and Volynetz, M.S., 1989. Research nots; pellet binder and steam pelleting as nitrogen correct ed true metabolizable energy contribus. Axample of a mixture. Poultry Science. 68: 22991302 .

Sogunle, O. M., Olatoye, B. B., Egbeyale, L. T., Jegede, A. V., Adeyemi, O. A., Ekunseitan, D. A., Bello, K. O., 2013. Feed forms of different particle sizes: Effects on growth performance, carcass characteristics, and intestinal villus morphology of cockerel chickens. Pacific J. Sci. Tech. 14: 405- 415 .

Svihus, B., Klovstad, K. H., Perez, V., Zimonja, O., Sahlstrom, S., Schuller, R. B., 2004 Physical and nutritional effects of pelleting of broiler chicken diets made from wheat ground to different coarsenesses by the use of roller mill and hammer mill. Animal Feed Science and Tec.: 117: 281 293.

Waldroup, P. W, Ristchie, S. J., Ramsey, B. E., 1982. Effects of lignosulfhonate pellet binder on pellet quality and feeding value for broiler. Feedstuffs 54:3. 33-35. 
Wamsley, K.G.S., Moritz, J. S., 2014. Assessment of diet formulation strategies that improve crumble quality and poult performance Appl. Poult. Res. 23 :639-646. http://dx.doi.org/ 10.3382/japr.2014-00972 Poult. Res. 22:439-446.

Zang, J. J., Piao, X. S., Huang, D. S., Wang, J. J., Ma, X., Ma, Y. X., 2009. Effects of feed particle size and feed form on growth performance, nutrient metabolizability and intestinal morphology in broiler chickens. Asian-Aust J Anim Sci, 22, pp. 107-112.

Zatari, I. M., Sell, J. L., 1990. Effect of pelleting diets containing sunflover meal on the performance of broiler chickens. Animal Feed Science and Technology. 30:1-2. 121-129. 